\title{
NOVEL HIGH-PERFORMANCE THIN-LAYER CHROMATOGRAPHIC METHOD FOR SIMPLE, ECONOMICAL, AND RAPID DETERMINATION OF FENOFIBRATE IN BULK AND PHARMACEUTICAL DOSAGE FORM
}

\author{
RANI S POTAWALE ${ }^{1 *}$, TABASSUM I HANGAD ${ }^{1}$ \\ Department of Pharmaceutical Chemistry, Allana College of Pharmacy, Pune, Maharashtra, India. Email: deshmukh_rani83@yahoo.co.in \\ Received: 18 December 2017, Revised and Accepted: 23 January 2018
}

\section{ABSTRACT}

Objective: A simple, novel, sensitive, and rapid high-performance thin-layer chromatographic (HPTLC) method has been developed and validated for quantitative determination of fenofibrate in bulk and formulations.

Methods: The chromatographic development was carried out on HPTLC plates precoated with silica gel $60 \mathrm{~F}_{254}$ using a single solvent dichloromethane as a simple mobile phase. Densitometric detection was carried out at $292 \mathrm{~nm}$.

Results: $\mathrm{R}_{f}$ value of drug was found to be $0.33 \pm 0.02$. The method was validated as per International Conference on Harmonization Guideline with respect to linearity, accuracy, precision, and robustness. The calibration curve was found to be linear over a range of $20-400^{\circ} \mathrm{ng}$ band $\mathrm{d}^{-10}$ with a regression coefficient of 0.999 . The method has proved high sensitivity and specificity.

Conclusion: Proposed densitometric method was found to be new, simple, and economic for routine quantification of fenofibrate in bulk and pharmaceutical formulation.

Keywords: Fenofibrate, High-performance thin-layer chromatographic, Single solvent analysis, Validation.

(C) 2018 The Authors. Published by Innovare Academic Sciences Pvt Ltd. This is an open access article under the CC BY license (http://creativecommons. org/licenses/by/4. 0/) DOI: http://dx.doi.org/10.22159/ajpcr.2018.v11i5.24240

\section{INTRODUCTION}

Fenofibrate is the lipid regulating drug. Chemically, it is propan-2yl2-[4-(4-chlorobenzoyl) phenoxy]-2-methyl propionate. Fenofibrate increases lipolysis and elimination of triglyceride-rich particles from plasma by activating lipoprotein lipase and reducing production of apoprotein C-III (an inhibitor of lipoprotein lipase activity) [1,2]. It is official in British pharmacopoeia [3]. The literature survey showed that there are some analytical methods reported for fenofibrate (Fig. 1) like spectrophotometric [4-8], high-performance liquid chromatographic [9-16], high-performance thin-layer chromatographic (HPTLC) $[17,18]$, and polarography analysis [19] either individually or in combination with other drug/s.

The present research manuscript describes a novel, simple, economical, accurate, and rapid HPTLC method developed in single solvent and validated in accordance with International Conference on Harmonization (ICH) Guidelines Q2 (R1) [20], for quantification of fenofibrate as a bulk drug and in its tablet dosage form.

\section{METHODS}

The fenofibrate pure standard was supplied by Emcure Pharmaceuticals Pvt. Ltd., Pune. Faint $160 \mathrm{mg}$ tablets (Franco-Indian Pharmaceuticals Pvt. Ltd.); labeled to contain $160 \mathrm{mg}$ fenofibrate, were obtained from the market. Analytical reagent grade chemicals were procured from Company Merck Specialties Pvt. Ltd. (Mumbai, India). Precoated silica gel HPTLC plates $60 \mathrm{~F}_{254}$ (E. Merck, Darmstadt, Germany) were used in the research.

\section{Instrumentation, chromatographic conditions}

The HPTLC instrument comprised a Linomat V sample applicator with a $100 \mu$ l Camag syringe with a TLC III scanner having WinCats Software Version 1.4.4. (Camag, Muttenz, Switzerland). The slit dimension was retained at $5 \times 0.45 \mathrm{~mm}$ and a scanning speed of $10 \mathrm{~mm} / \mathrm{s}$ was maintained. Prewashed HPTLC plates were activated at $120^{\circ} \mathrm{C}$ for 15 min before analysis.

HPTLC plates were then developed in a Camag $20 \times 10 \mathrm{~cm}$ twin trough chamber (Camag, Muttenz, Switzerland) with $20 \mathrm{ml}$ mobile phase comprising only dichloromethane. The optimized chamber saturation time for solvent system was $15 \mathrm{~min}$ at room temperature $\left(25 \pm 2^{\circ} \mathrm{C}\right)$. The length of chromatographic run was $80 \mathrm{~mm}$. After chromatographic development, plates were dried in an air current. Densitometric scanning was performed in the reflectance-absorbance mode at $292 \mathrm{~nm}$ by Camag TLC Scanner III using WinCats Software Version 1.4.4.

\section{Preparation of standard stock solutions}

Standard stock solution of fenofibrate was prepared individually by dissolving $10 \mathrm{mg}$ of standard drug in $10 \mathrm{ml}$ methanol to get concentration of $1000 \mu \mathrm{g} / \mathrm{ml}$ and from this $1 \mathrm{ml}$ further diluted to get $100 \mu \mathrm{g} / \mathrm{ml}$ concentrations.

Selection of detection wavelength

Fenofibrate showed significant absorbance at $292 \mathrm{~nm}$ and thus was selected for densitometric analysis (Fig. 2).

\section{Preparation of sample solutions}

For the study of marketed tablet dosage form, 20 tablets were accurately weighed. The average weight was assessed and tablets were crushed to get fine powder. Powder equivalent to $5 \mathrm{mg}$ of fenofibrate was weighed and shifted to the volumetric flask $(50 \mathrm{ml})$ containing $20 \mathrm{ml}$ methanol. The solution was sonicated for $15 \mathrm{~min}$, diluted up to the mark with solvent methanol. The solution was filtered through Whatman filter paper (No. 41). The resulting solution is used for further study.

\section{Assay validation}

The proposed HPTLC method was validated as per the guidelines of the ([ICH] Q2 [RI]) for various parameters. 


\section{Linearity and range}

On the HPTLC plate, a stock solution was applied in the concentration of 20-400 ng band ${ }^{-1}$ of fenofibrate to evaluate linearity. The graph of peak area versus concentration was plotted. Least square linear regression analysis was done. The correlation coefficient, intercept, and slope were calculated.

\section{Sensitivity}

Limit of detection (LOD) and limit of quantitation (LOQ) was calculated using formula $3.3 \sigma / \mathrm{S}$ and $10 \sigma / \mathrm{S}$, respectively, where $\sigma$ is the standard deviation of the response ( $y$-intercept) and $S$ is the slope of the linearity plot.

\section{Specificity}

The peak purity for fenofibrate was assessed by comparing ultraviolet (UV) spectrum acquired at the start (S), apex (M), and end (E) of the peak obtained from the scanning of the band.

\section{Precision studies}

Precision was calculated by intra- and inter-day precision studies. $100 \mathrm{ng}_{\text {band }}{ }^{-1}$ fenofibrate sample was analyzed 6 times on the similar day to find out any differences in the results. Interday precision study was done on 3 successive days.

\section{Accuracy studies}

By estimating recovery of fenofibrate by the standard addition method, the accuracy was determined. The samples were spiked at three levels with 80,100 , and $120 \%$ of $100 \mathrm{ng}^{\text {band }}{ }^{-1}$ of the fenofibrate standard solution. Recovery was assessed from the following equation:

([Spiked concentration-mean concentration]/spiked concentration)×100

\section{Robustness studies}

The effect of small but deliberate variations in method parameters such as the volume and composition of the mobile phase, time from spotting to development, and development to scanning were evaluated in this study. Only one parameter was varied at a time. $100 \mathrm{ng} \mathrm{band}^{-1}$ concentration of fenofibrate was used in six replicates to study

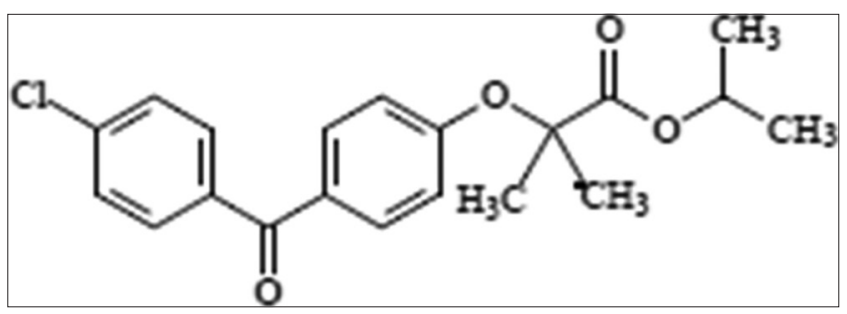

Fig. 1: Chemical structure of fenofibrate

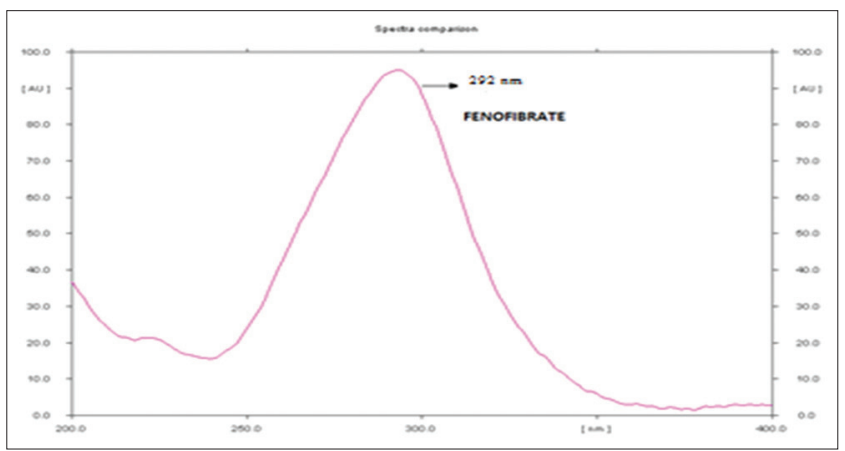

Fig. 2: Spectrum obtained from standard solution of fenofibrate robustness of the method. The standard deviation of peak areas and \% relative standard deviation (RSD) was determined.

\section{RESULTS AND DISCUSSION}

\section{Chromatographic development}

Different solvent systems were tried, to accomplish the $\mathrm{R}_{f}$ value in the range $0.2-0.8$, and minimum resolution Rs $\geq 1.5$. Finally, the mobile phase consisting of only dichloromethane was selected for obtaining sharp peak and promising results. The retention factors were found to be $0.33 \pm 0.02$ for fenofibrate (Fig. 3).

\section{Validation of the method}

Linearity

The analyte response was linear $\left(r^{2}=0.999\right)$ for fenofibrate over the concentration range between 20 and $400 \mathrm{ng} \mathrm{band}^{-1}$. The results were shown in Table 1. Calibration curve was constructed as described and showed acceptable accuracy and precision over a wide concentration range. Results demonstrate that an excellent correlation between the absorbance and concentration of fenofibrate drug substances. To ascertain linearity, residual analysis was performed (Fig. 4).

Table 1: Linear regression data for the calibration curves $(n=6)$

\begin{tabular}{ll}
\hline Parameters & \\
\hline Linearity range (ng/band) & $20-400$ \\
$\mathrm{r}^{2}$ & 0.999 \\
Slope & 21.24 \\
Intercept & 492.55 \\
Confidence limit of slope $^{\mathrm{a}}$ & $20.84-21.65$ \\
Confidence limit of intercept $^{\mathrm{a}}$ & $409.19-575.90$ \\
Sy.x & 33.75 \\
\hline
\end{tabular}

a: $95 \%$ confidence limit, Sy.x: Standard deviation of residuals from line

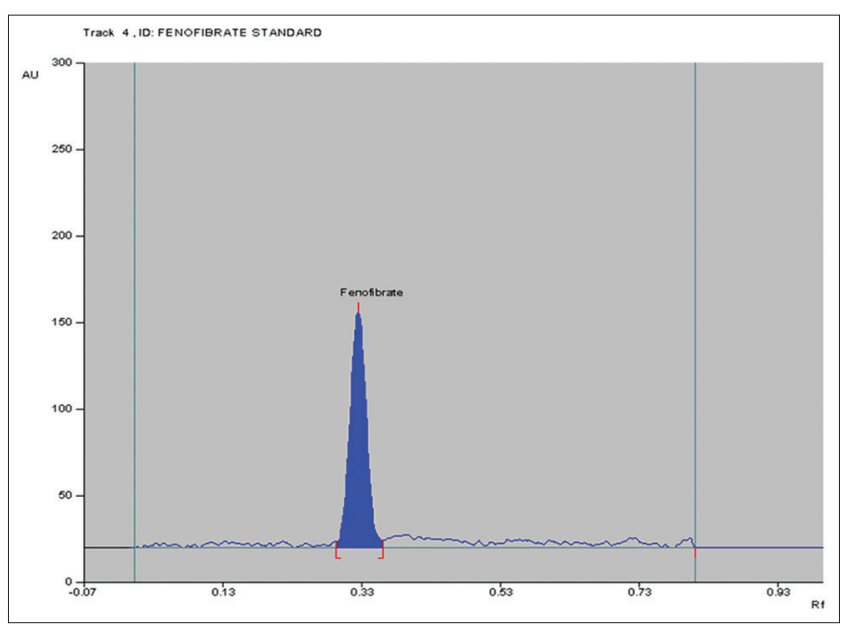

Fig. 3: Densitogram obtained from standard solution of fenofibrate scanned at $292 \mathrm{~nm}$

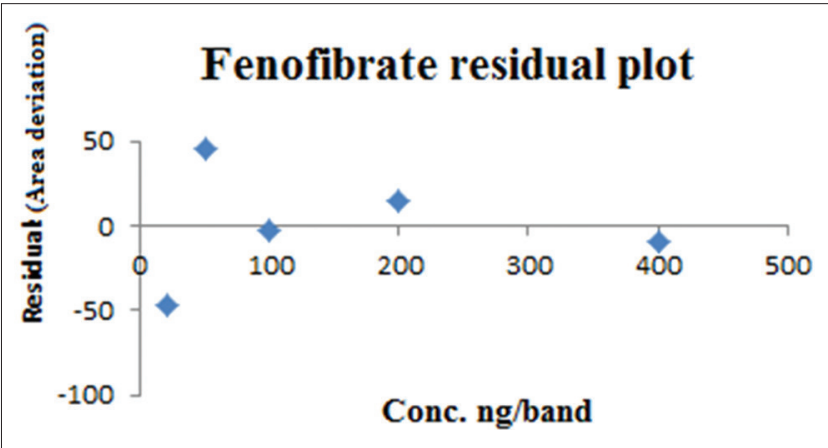

Fig. 4: Concentration residual plot of fenofibrate 


\section{Sensitivity}

The LOD was found to be $5.24 \mathrm{ng}_{\text {band }}{ }^{-1}$ for fenofibrate. The LOQ for fenofibrate was found to be $15.89 \mathrm{ng} \mathrm{band}^{-1}$, representing good sensitivity of the method.

\section{Specificity}

The peak purity for fenofibrate was assessed by comparing UV spectrum acquired at the start (S), apex (M), and end (E) of the peak obtained from the scanning of band, that is, $r(S, M)=0.998,0.998$ and $r(M, E)=0.998,0.998$, respectively. Peak purity data showed that peak obtained for fenofibrate was pure and method is specific.

\section{Precision}

Intra- and inter-day variation in estimation of fenofibrate (Table 2) showed that the $\%$ RSD was $<2 \%$ during the analysis. These low values of RSD show that the precision of the method is good.

\section{Accuracy}

The study of accuracy reveals influences of additives that are usually present in the dosage forms on the quantitative parameters. The recovery study data presented in Table 3 indicates that the accuracy of the quantification of fenofibrate was more than $98 \%$, which indicate that the proposed simultaneous densitometric method is reliable for the estimation of fenofibrate in the marketed formulation used in the study.

\section{Robustness studies}

The $\%$ RSD of peak areas was calculated for each parameter and was found to be $<2 \%$ (Table 4 ).

\section{Analysis of a marketed preparation}

The results obtained for the amount of fenofibrate in tablets as against the label claims were in good agreement signifying that there is no interference from any of the excipients presents in tablets. The percent

Table 2: Intra- and inter-day precision of the HPTLC method (n=6)

\begin{tabular}{llll}
\hline Drug & $\begin{array}{l}\text { Actual concentration } \\
\text { intra-/inter-day }\end{array}$ & Intra-/inter-day & (\%) RSD \\
\hline Fenofibrate & 100 & $98.52 / 99.34$ & $0.69 / 1.00$ \\
\hline n: Number of determinations, a: ng band ${ }^{-1}$, & RSD: Relative standard deviation. \\
HPTLC: High-performance thin-layer chromatographic
\end{tabular}

Table 3: Results of recovery studies $(n=6)$

\begin{tabular}{llll}
\hline $\begin{array}{l}\text { Amount } \\
\text { taken }^{\mathbf{a}}\end{array}$ & $\begin{array}{l}\text { Amount } \\
\text { added }^{\mathrm{a}}\end{array}$ & $\begin{array}{l}\text { Amount } \\
\text { found }^{\mathbf{a}}\end{array}$ & Recovery $\pm \%$ RSD \\
\hline 100 & 80 & 179.06 & $99.48 \pm 0.93$ \\
100 & 100 & 200.43 & $100.21 \pm 1.09$ \\
100 & 120 & 218.96 & $99.53 \pm 0.86$ \\
\hline
\end{tabular}

n: Number of determinations, a: ng band ${ }^{-1}$, RSD: Relative standard deviation

Table 4: Robustness testing ( $\mathrm{n}=6,100 \mathrm{ng}$ band $\left.^{-1}\right)$

\begin{tabular}{ll}
\hline Parameter varied & \% RSD \\
\hline $\begin{array}{l}\text { Mobile phase (ethyl acetate) } \\
\text { composition }( \pm 0.1 \mathrm{ml})\end{array}$ & 0.50 \\
$\begin{array}{l}\text { Amount of mobile phase }( \pm 5 \%) \\
\text { Time from band application to } \\
\text { chromatography }( \pm 10 \text { min) } \\
\begin{array}{l}\text { Time from chromatography to } \\
\text { scanning ( } \pm 15 \text { min) }\end{array}\end{array}$ & 1.01 \\
\hline
\end{tabular}

$\mathrm{n}$ : Number of determinations, RSD: Relative standard deviation assay was found to be $98.47 \%$, for fenofibrate, in marketed formulation in six replicate determinations.

\section{CONCLUSION}

In the present research work, an attempt has been made to develop and validate a quick, precise, and accurate method based on normalphase HPTLC has been developed for routine analysis of fenofibrate in fixed-dose combination tablets. The method was validated for linearity, precision, accuracy, and specificity. It is cheap, quick and does not use chloroform and combination of solvents, therefore, suitable for routine analysis of fenofibrate in fixed-dose combination tablets. When compared with the reported HPTLC method, the developed HPTLC method is both time and cost-effective for the determination of fenofibrate.

\section{ACKNOWLEDGMENTS}

Authors are also thankful to Principal Dr. (Mrs.) KiranBhise, the Management of M.C.E. Society's Allana College of Pharmacy, Pune, India, for providing necessary research facilities and Public Testing Laboratory, Erandwane, Pune, Maharashtra, India, for providing technical support and facilities to carry out research work. The authors also express their gratitude to Emcure Pharmaceuticals Limited, Pune, Maharashtra, India, for providing a gift sample of pure drugs.

\section{CONFLICT OF INTERESTS}

The authors have no conflict of interest

\section{REFERENCES}

1. Potawale RS, Gabhe SY. HPTLC method for simultaneous determination of rosuvastatin and fenofibrate in bulk and pharmaceutical formulation. Int J Pharm Pharm Sci 2014;6:323-6.

2. Budavari S. The Merck Index: An Encyclopedia of Chemicals, Drugs and Biological. Vol. 4. Whitehouse Station: Merck and Co.; 1996. p. 3978.

3. British Pharmacopoeia. British Pharmacopoeia Commission Secretariat of the Medicines and Healthcare products Regulatory Agency. Vol. 4. London: Stationary Office; 2009. p. 2456.

4. Gupta KR, Askarkar SS, Rathod PP, Wadodkar SG. Validated spectrophotometric determination of fenofibrate in formulation. Pharm Sin 2010;1:173-8.

5. Kondawar MS, Kamble KG, Maharshi KH, Khandare MM. UV Spectrophotometric estimation of ezetimibe and fenofibrate in bulk drug and dosage form using simultaneous equation method. Int $\mathrm{J}$ Chemtech Res 2011;3:749-54.

6. Sevda RR, Ravetkar AS, Shirote PJ. UV spectrophotometric estimation of rosuvastatin calcium and fenofibrate in bulk drug and dosage form using simultaneous equation method. Int $\mathrm{J}$ Chemtech Res 2011;3:629-35

7. Mandwal PS, Patel PR, Agarwal KM, Surana SJ. Q-Absorbance and multicomponent UV-spectrophotometric methods for simultaneous estimation of rosuvastatin calcium and fenofibrate in pharmaceutical formulation. Pharm Lett 2012;4:1054-9.

8. Fathy MM, Mohamed WI, Mohie MK, Khalid AM, Mohamed YK. Determination of fenofibrate and the degradation product using simultaneous UV-derivative spectrometric method and HPLC. Am J Anal Chem 2011;2:332-43.

9. Khaleel N, Rahaman A. Validated stability indicating RP-HPLC method for simultaneous determination of atorvastatin, fenofibrate and folic acid in bulk and pharmaceutical dosage form. Pharm Lett 2016;8:13-32.

10. Gurram SC. RP-HPLC method development and validation for the simultaneous estimation of atorvastatin, fenofibrate and ezetimibe in a pharmaceutical dosage form. Biochem Anal Biochem 2015;4:1-4.

11. Rekha R, Kuma PR. Validated stability-indicating isocratic RP-HPLC method of determination of rosuvastatin calcium and fenofibrate in bulk and in solid dosage by vieordt's method. Am J Pharmtech Res 2017:7:465-78

12. Abid MY, Dong WK, Han GC, Euichaul O. Validation of a highly sensitive RP-HPLC method for quantification of fenofibrate in pure and pharmaceutical dosage forms. Curr Pharm Anal 2014;10:97-104.

13. Samyukta E, Srinivas P. Stability indicating method development and 
validation of choline fenofibrate in pharmaceutical dosage forms by RP-HPLC. Int J Pharm Sci Res 2014;5:849-54.

14. Sahu PK, Murthy Pyla SR, Srinivas K, Swain S. Simultaneous RPHPLC method development and validation of atorvastatin, ezetimibe and fenofibrate. Pharm Reg Aff 2016;5:1-6.

15. Bhinge SD, Malipatil SM, Jondhale A, Hirave R, Savalia S. New approach to the RP-HPLC method for simultaneous estimation of atorvastatin calcium and fenofibrate in pharmaceutical dosage forms. Eur J Chem 2012;9:1223-9.

16. Karunakaran A, Subhash V, Chinthala R, Muthuvijayan J. Simultaneous estimation of rosuvastatin calcium and fenofibrate in bulk and in tablet dosage form by UV-spectrophotometry and RP-HPLC. J Pharm Sci 2011;4:58-63.
17. Macwana CR, Patel AJ, Parmar VM, Patel SG. Simultaneous HPTLC analysis of atorvastatin calcium, ezetimibe, and fenofibrate in tablet. J Liq Chromatogr Relat Technol 2012;35:524-32.

18. Rao S, Rao P, Dadhich AS, Rao MK. Simultaneous determination of atorvastatin, ezetimibe and fenofibrate in tablets by planar chromatography with confirmation by electrospray ionization mass spectrometry. Int J Res Pharm Chem 2017;7:51-9.

19. Ramadan AA, Mandil H, Abu-Saleh R. Development and validation of differential pulse polarographic analysis of fenofibrate in pure and pharmaceutical dosage forms using dropping mercury electrode. Int $\mathrm{J}$ Pharm Pharm Sci 2016;8:284-9.

20. International Conference on Harmonization. ICH Harmonized Tripartite Guideline Validation of Analytical Procedures: Text and Methodology Q2 (R1). Geneva: ICH; 2005. 